\title{
Association between ADIPOQ rs2241766 polymorphism and risk of diabetic nephropathy
}

\author{
Hanyu Zhu ${ }^{1, *}$, Dong Zhang ${ }^{1, *}$, Wenjia Geng ${ }^{1}$, Ying Zheng ${ }^{1}$, Jie Wu ${ }^{1}$, Zheyi Dong ${ }^{1}$, \\ Weiguang Zhang ${ }^{1}$, Fenglin Xiao ${ }^{1}$, Moyan Liu ${ }^{1}$, Zuoxiang Li $^{1}$, Shuwei Duan ${ }^{1}$, \\ Guangyan Cai ${ }^{1}$ and Xiangmei Chen ${ }^{1}$ \\ ${ }^{1}$ Department of Nephrology, Chinese PLA General Hospital, Chinese PLA Institute of Nephrology, State Key Laboratory of Kidney \\ Diseases, National Clinical Research Center of Kidney Diseases, Beijing Key Laboratory of Kidney Disease, Beijing, China \\ *These authors contributed equally to this work
}

Correspondence to: Xiangmei Chen, email: xianmeihguiid@163.com

Keywords: ADIPOQ; polymorphism; diabetic nephropathy; susceptibility

Received: June 30, $2016 \quad$ Accepted: September 21, $2016 \quad$ Published: August 03, 2017

Copyright: Zhu et al. This is an open-access article distributed under the terms of the Creative Commons Attribution License 3.0 (CC BY 3.0), which permits unrestricted use, distribution, and reproduction in any medium, provided the original author and source are credited.

\section{ABSTRACT}

Background: This meta-analysis was performed to derive a more comprehensive estimation over the role of the single nucleotide polymorphism (SNP) rs2241766 in ADIPOQ gene in the occurrence of DN.

Results: The overall ORs reflected a positive correlation between ADIPOQ rs2241766 polymorphism and susceptibility to DN under GG vs. TT and GG vs. TT + TG comparisons $(O R=1.51,95 \% C I=1.16-1.95 ; O R=1.43,95 \% C I=1.11-1.85)$. After stratification analyses by ethnicity and disease type, a similar trend was also revealed in Caucasian and African subgroups as well as in type 2 diabetes mellitus (T2DM) subgroup.

Materials and Methods: Relevant studies were searched from digital databases such as Embase, PubMed, Wanfang, and Chinese National Knowledge Infrastructure (CNKI). Odds ratios (ORs) with their corresponding $95 \%$ confidence intervals ( $95 \%$ CIs) were pooled by means of fixed- or random-effects models. Inter-study heterogeneity was examined using $Q$ test and $\mathrm{I}^{2}$ statistic, and sensitivity analysis was implemented to test the statistical stability of overall estimates. Begg's funnel plot and Egger's test were applied to inspect potential publication bias among included studies.

Conclusions: ADIPOQ rs2241766 polymorphism may be associated with an increased risk of DN, especially in Caucasian and African populations as well as in T2DM patients.

\section{INTRODUCTION}

In diabetic patients, microvascular lesions and accelerated atherosclerosis tend to trigger complications leading to severe morbidity [1]. Diabetic nephropathy $(\mathrm{DN})$ is a representative microvascular complication in type 1 and type 2 diabetes mellitus (T1DM and T2DM) which can cause end-stage renal disease (ESRD) [2-4]. Reports show that about one third of diabetic patients will finally develop DN, so it is of great significance to find risk factors for DN occurrence [5]. Patients suffering from DN may require hemodialysis or even kidney transplantation in the end, thus causing serious economic burden on health care budgets $[6,7]$. DN is a multifactorial disease occurring as a result of both environmental and hereditary factors [8]. The ethnic disparity in DN development may be attributed to an important role of genetic factors; and gender has also been demonstrated to influence the predisposition of diabetic patients to developing kidney diseases, with males having a relatively higher incidence rate $[8-11]$.

One of the candidate genes for $\mathrm{DN}$ is adiponectin ( $A D I P O Q)$, which has been indicated to be linked to the susceptibility to cardiovascular disease, metabolic syndrome, and T2DM [12]. The ADIPOQ gene mapped to chromosome $3 \mathrm{q} 27$ is consisted of three exons and two introns [13-15]. This adipokine can exert antiinflammatory and anti-atherogenic effects and regulate glucose and lipid metabolism as well as insulin action $[16,17]$. The chromosomal region containing the $A D I P O Q$ 
gene has been reported to be one of the cardiovascular risk factors as well [18, 19]. Additionally, abnormal levels of serum adiponectin have already been shown to be correlated with T2DM, insulin resistance, obesity, cardiovascular diseases and nephropathy [8, 16, 20-22]. Reportedly, the development of microalbuminuria in T1DM cases may be predicted by high adiponectin levels [23]. Several single nucleotide polymorphisms (SNPs) have been identified in the $A D I P O Q$ gene and their associations with the risk of $\mathrm{DN}$ in T1DM and T2DM patients have been investigated in diverse populations in many case-control studies, but the results remain inconclusive.

In the present meta-analysis, we selected one commonly-studied SNP rs2241766 in exon 2 of $A D I P O Q$ gene to clarify its effects on DN occurrence based on previously published case-control studies on this topic.

\section{RESULTS}

\section{Characteristics of studies}

The publication search is described in Figure 1. Initially, altogether 174 articles were identified from the database search. During the further reviewing, 163 articles were deleted for editorials (7), on rats (6), not about DN or merely about diabetes (63), obvious irrelevancy (71), concerning the prognosis of DN (8), meta-analysis (3), and with no detailed data about genotype and allele frequencies (5). At last, 14 case-control studies with 3343 cases and 7859 controls were incorporated into the present meta-analysis [1, 20, 24-32]. All of the controls in our meta-analysis were diabetic patients without nephropathy. Additionally, the most of included studies were high-quality
(NOS score more than 6). Table 1 summarizes general characteristics of the incorporated studies.

\section{Meta-analysis results}

The relationship between $A D I P O Q$ rs2241766 polymorphism and DN susceptibility is illustrated in Table 2. The combined results demonstrated that $A D I P O Q$ rs2241766 polymorphism increased the susceptibility to DN under two genetic comparisons of GG vs. TT (Figure 2) and GG vs. TT + TG (OR = 1.51, $95 \% \mathrm{CI}=1.16-1.95 ; \mathrm{OR}=1.43,95 \% \mathrm{CI}=1.11-1.85)$. A risk-increasing effect of the polymorphism was also shown in Caucasian (GG + TG vs. TT: OR $=1.27,95 \%$ $\mathrm{CI}=1.01-1.60$; allele $\mathrm{G}$ vs. allele $\mathrm{T}: \mathrm{OR}=1.12,95 \%$ $\mathrm{CI}=1.01-1.25)$, African (GG vs. TT: OR $=9.06,95 \%$ $\mathrm{CI}=3.00-27.34$ (Figure 2); GG + TG vs. TT: OR =4.80, $95 \% \mathrm{CI}=2.86-8.03 ; \mathrm{GG}$ vs. $\mathrm{TT}+\mathrm{TG}: \mathrm{OR}=4.34$, $95 \% \mathrm{CI}=1.48-12.68$; allele $\mathrm{G}$ vs. allele $\mathrm{T}: \mathrm{OR}=3.16$, $95 \%$ CI $=2.12-4.71 ;$ TG vs. TT: $\mathrm{OR}=4.26,95 \%$ $\mathrm{CI}=2.50-7.28$ ), and T2DM (GG vs. TT+TG: OR $=1.68$, $95 \% \mathrm{CI}=1.18-2.39$ ) groups after subgroup analyses by ethnicity and disease type.

\section{Heterogeneity test}

The statistical $Q$ test and $\mathrm{I}^{2}$ statistic revealed significant heterogeneity under $\mathrm{GG}+\mathrm{TG}$ vs. TT, G vs. T and TG vs. TT contrasts, so the random-effects model was chosen for calculating ORs in these cases, while the fixed-effects model was adopted under the other two genetic comparisons where heterogeneity was negligible.

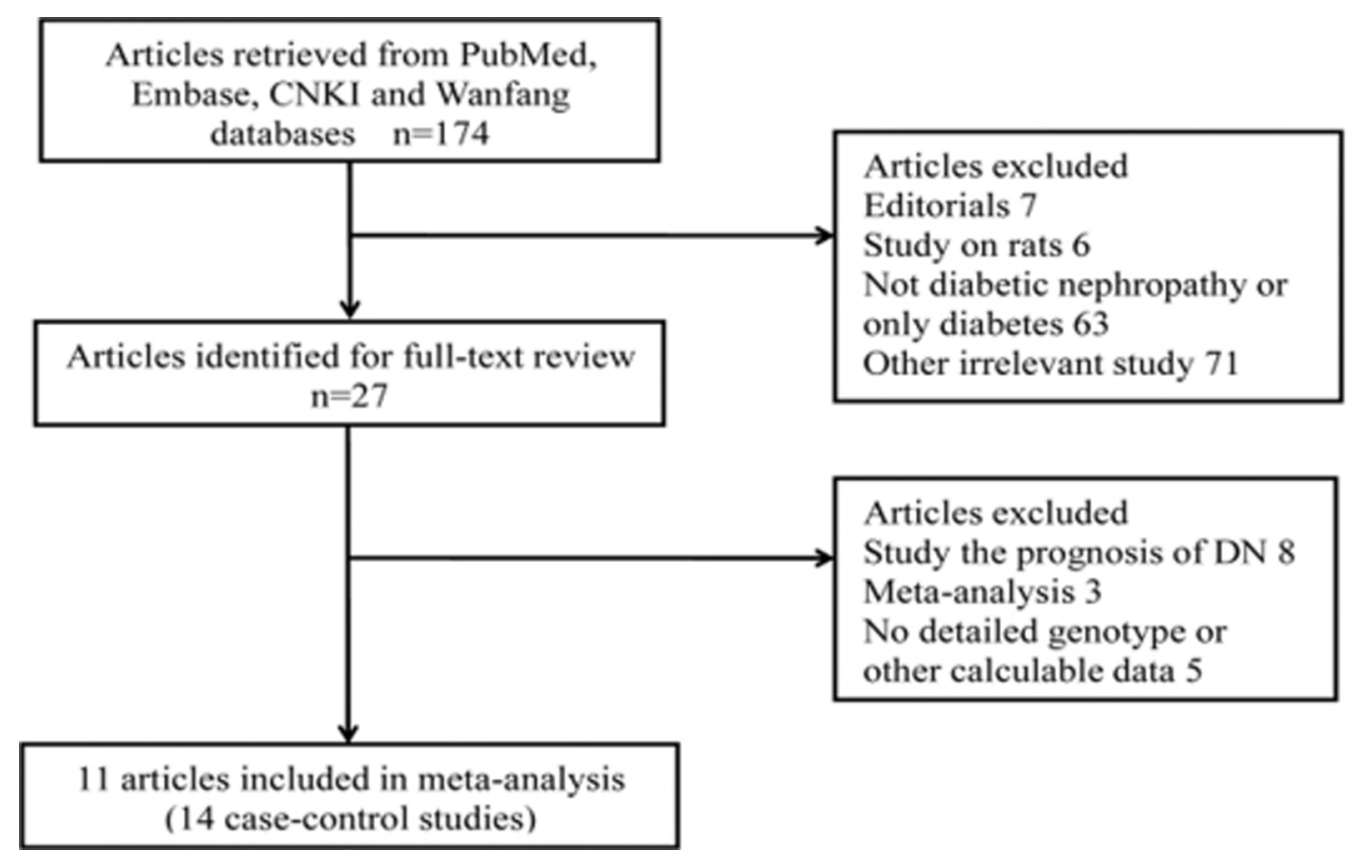

Figure 1: Flowchart illustrating the process of study identification, inclusion and exclusion. 
Table 1: Main characteristics of included studies of the present meta-analysis

\begin{tabular}{|c|c|c|c|c|c|c|c|c|c|c|c|c|c|c|c|c|c|}
\hline \multirow{2}{*}{$\begin{array}{c}\text { First } \\
\text { author } \\
\text { (year) }\end{array}$} & \multirow{2}{*}{ Country } & \multirow{2}{*}{ Ethnicity } & \multirow{2}{*}{$\begin{array}{l}\text { Control } \\
\text { source }\end{array}$} & \multirow{2}{*}{ Type } & \multirow{2}{*}{$\begin{array}{c}\text { Sample } \\
\text { size }\end{array}$} & \multicolumn{5}{|c|}{ Case genotype and allele } & \multicolumn{5}{|c|}{$\begin{array}{l}\text { Control genotype and } \\
\text { allele }\end{array}$} & \multirow[t]{2}{*}{$\begin{array}{c}\text { Genotyping } \\
\text { method }\end{array}$} & \multirow[t]{2}{*}{$\begin{array}{l}\text { NOS } \\
\text { score }\end{array}$} \\
\hline & & & & & & TT & TG & GG & $\mathbf{T}$ & G & TT & TG & GG & $\mathbf{T}$ & $\mathbf{G}$ & & \\
\hline Ma (2007) & Sweden & Caucasian & Diabetic & T1DM & $196 / 236$ & 180 & 15 & 1 & 375 & 17 & 213 & 22 & 1 & 448 & 24 & PCR-DASH & 7 \\
\hline Choe (2013) & Korea & Asian & Diabetic & T2DM & $245 / 448$ & 124 & 95 & 26 & 343 & 147 & 216 & 204 & 28 & 636 & 260 & SNaPShot & 7 \\
\hline $\begin{array}{l}\text { Chung } \\
\text { (2014) }\end{array}$ & China & Asian & Diabetic & T2DM & $144 / 422$ & 77 & 57 & 10 & 211 & 77 & 206 & 186 & 30 & 598 & 246 & $\begin{array}{l}\text { multiplex } \\
\text { PCR }\end{array}$ & 8 \\
\hline $\begin{array}{l}\text { El-Shal } \\
(2014)\end{array}$ & Egypt & African & Diabetic & T2DM & $196 / 100$ & 53 & 113 & 30 & 219 & 173 & 64 & 32 & 4 & 160 & 40 & PCR-RFLP & 7 \\
\hline $\begin{array}{c}\text { Jaziri } \\
(2010)\end{array}$ & France & Caucasian & Diabetic & T2DM & $75 / 3011$ & 46 & 25 & 4 & 117 & 33 & 2223 & 728 & 60 & 5174 & 848 & PCR-MB & 8 \\
\hline Peng (2012) & China & Asian & Diabetic & T2DM & $42 / 40$ & 25 & 14 & 3 & 64 & 20 & 19 & 18 & 3 & 56 & 24 & DS & 7 \\
\hline $\begin{array}{l}\text { Ranjbar } \\
(2011)\end{array}$ & Iran & Caucasian & Diabetic & T2DM & $28 / 205$ & 20 & 8 & 0 & 48 & 8 & 142 & 56 & 7 & 340 & 70 & PCR-RFLP & 7 \\
\hline $\begin{array}{l}\text { Sikka } \\
(2014)\end{array}$ & India & Asian & Diabetic & T2DM & $145 / 152$ & 124 & 20 & 1 & 268 & 22 & 128 & 22 & 2 & 278 & 26 & PCR-RFLP & 6 \\
\hline $\begin{array}{l}\text { Vionnet } \\
(2006)\end{array}$ & Denmark & Caucasian & Diabetic & T1DM & $489 / 463$ & 393 & 91 & 5 & 877 & 101 & 377 & 82 & 4 & 836 & 90 & Ampli-Fluor & 7 \\
\hline $\begin{array}{l}\text { Vionnet } \\
(2006)\end{array}$ & Finland & Caucasian & Diabetic & T1DM & $387 / 469$ & 349 & 37 & 1 & 735 & 39 & 416 & 51 & 2 & 883 & 55 & Ampli-Fluor & 7 \\
\hline $\begin{array}{l}\text { Vionnet } \\
(2006)\end{array}$ & France & Caucasian & Diabetic & T1DM & $300 / 391$ & 221 & 73 & 6 & 515 & 85 & 303 & 82 & 6 & 688 & 94 & Ampli-Fluor & 7 \\
\hline $\begin{array}{l}\text { Blech } \\
(2011)\end{array}$ & Israel & Caucasian & Diabetic & $\begin{array}{l}\text { T2DM or } \\
\text { T1DM }\end{array}$ & $852 / 1473$ & 532 & 283 & 37 & 1347 & 357 & 966 & 454 & 53 & 2386 & 560 & $\begin{array}{c}\text { Not } \\
\text { available }\end{array}$ & 7 \\
\hline $\begin{array}{l}\text { Rudofsky } \\
\text { (2004) }\end{array}$ & Germany & Caucasian & Diabetic & T1DM & $73 / 166$ & 47 & & 26 & / & / & 147 & & 19 & / & / & PCR-RFLP & 8 \\
\hline $\begin{array}{l}\text { Rudofsky } \\
\text { (2004) }\end{array}$ & Germany & Caucasian & Diabetic & T2DM & $174 / 283$ & 137 & & 37 & l & / & 239 & & 44 & / & l & PCR-RFLP & 8 \\
\hline
\end{tabular}

PCR: polymerase chain reaction; PCR-RFLP: PCR-restriction fragment length polymorphism; PCR-MB: PCR-molecular beacon; PCRDASH: PCR-dynamic allele specific hybridization; DS: Direct sequencing.

Under the three contrasts where significant heterogeneity was revealed, meta regression analysis was conducted, and the results demonstrated that differences in ethnic origin could explain the vast majority or even total of the sources of the significant heterogeneity.

\section{Sensitivity analysis}

In sensitivity analysis, recalculated ORs after removing any one single eligible study showed no qualitative difference from original ones (Figure 3, with a lower CI of 1.01 and an upper CI of 2.29), implying that our results were reliable and robust.

\section{Publication bias}

Potential publication bias among the included studies was assessed through the visual inspection of Begg's funnel plots accompanied by statistical result from Egger's test. The symmetrical shape of the funnel plots (Figure 4) and $P$ value of Egger's linear regression test $(P=0.520)$ indicated the absence of significant publication bias.

\section{DISCUSSION}

According to existing evidences, chronic kidney failure, renal failure, and high adiponectin levels in T1DM and T2DM patients may be all related to nephropathy pathogenesis [23, 33-37]. The adiponectin protein encoded by the $A D I P O Q$ gene can prevent vascular remodeling by inhibiting the proliferation and migration of smooth muscle cells and reduce TNF- $\alpha$ production to modulate the inflammatory response of endothelial cells $[38,39]$. In addition, adiponectin can protect vasculature through its pleiotropic actions on endothelial progenitor cells, endothelial cells, macrophages, and smooth muscle cells [40]. What's more, it may also prevent the injury and dysfunction of endothelial cells due to its protective effects [40]. Genetic polymorphisms in the $A D I P O Q$ gene can affect the adiponectin levels, and their contribution to occurrence of $\mathrm{DN}$, a common micorvascular complication, has been frequently discussed, but conflicting results are yielded.

We therefore performed the present meta-analysis including 3343 cases and 7859 controls aiming to obtain a better insight into the linkage between ADIPOQ rs2241766 polymorphism and DN risk. After data syntheses, we 


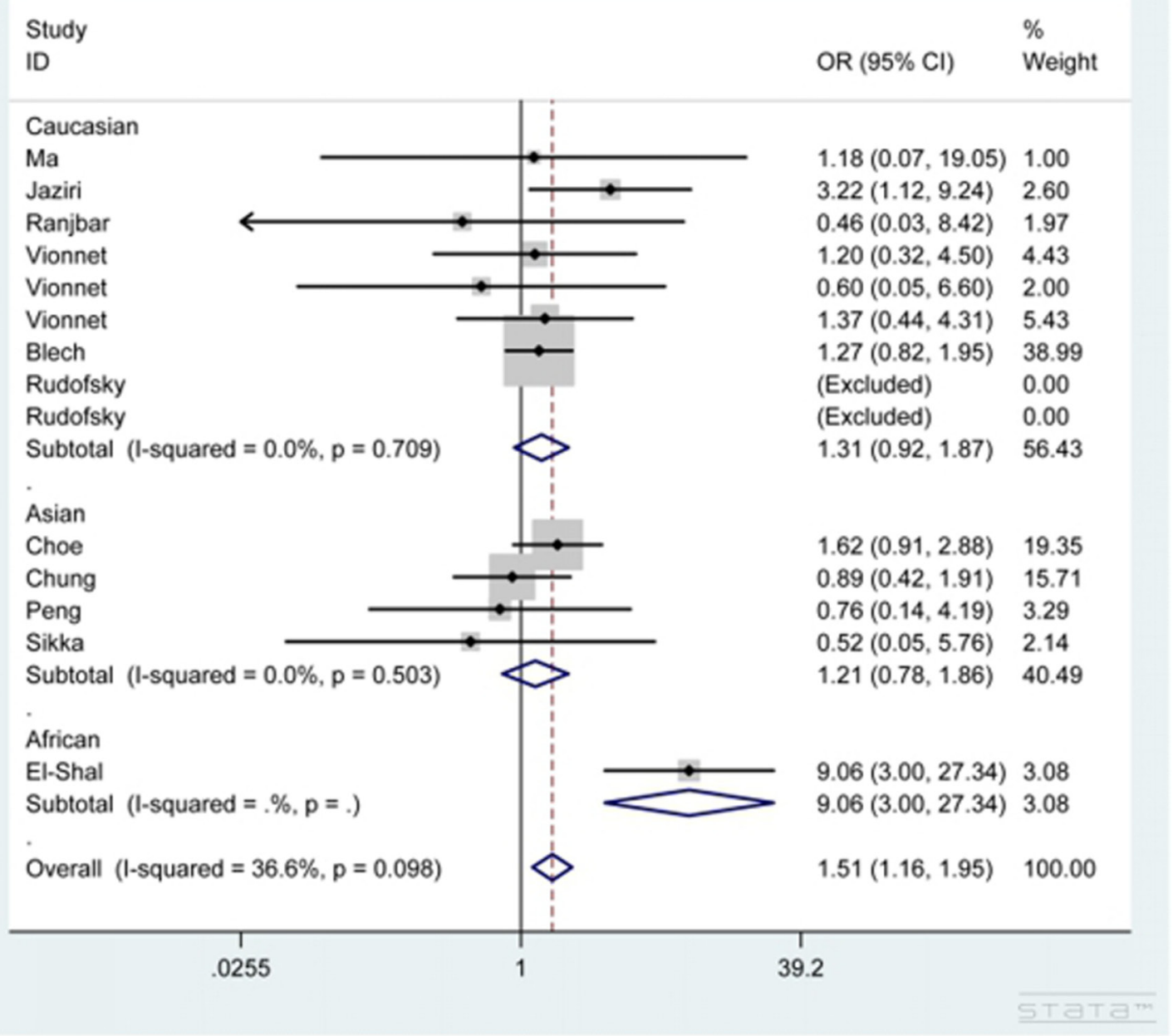

Figure 2: Forest plot for the association between $A D I P O Q$ rs2241766 polymorphism and DN risk under GG vs. TT contrast. The squares and horizontal lines correspond to the study-specific OR and $95 \%$ CI. The area of the squares reflects the weight (inverse of the variance). The diamond represents the summary OR and 95\% CI.

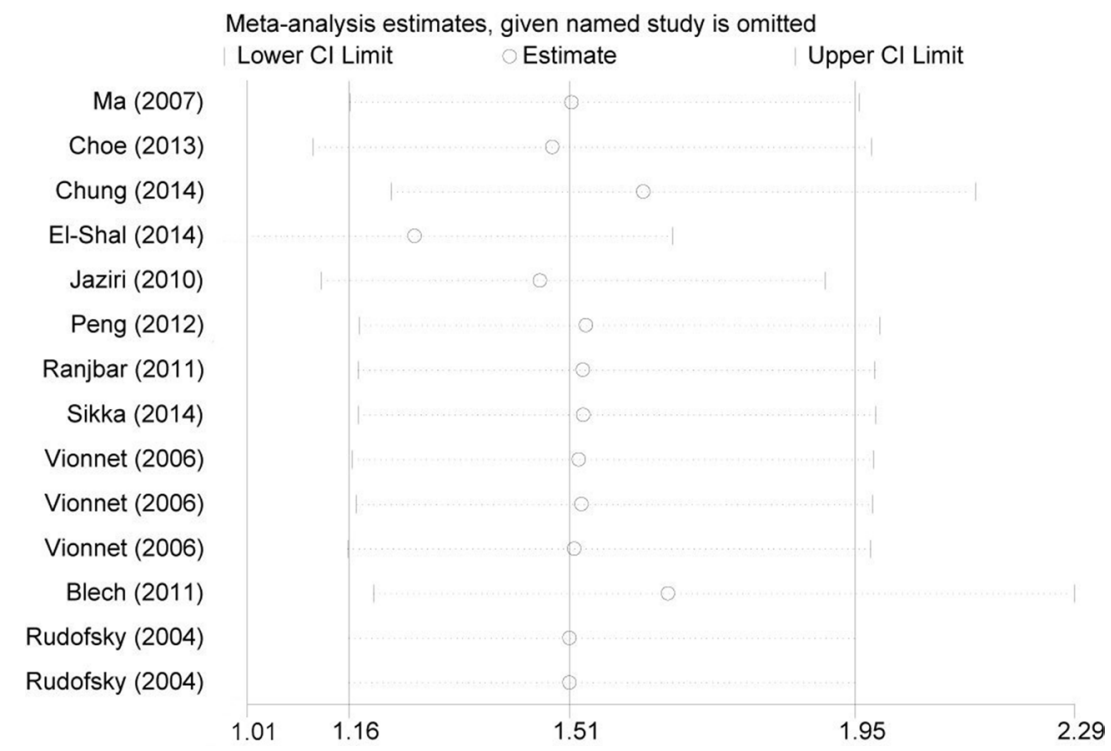

Figure 3: Sensitivity analysis for test the stability of overall estimate under GG vs. TT contrast. 
Table 2: Meta-analysis of the association between $A D I P O Q$ rs2241766 polymorphism and DN risk

\begin{tabular}{|c|c|c|c|c|c|c|c|c|}
\hline \multirow[b]{2}{*}{ Model } & \multicolumn{4}{|c|}{ Ethnicity } & \multicolumn{3}{|c|}{ Type } & \multirow[b]{2}{*}{ Total } \\
\hline & & Caucasian & Asian & African & T1DM & T2DM & $\begin{array}{l}\text { T2DM or } \\
\text { T1DM }\end{array}$ & \\
\hline \multirow{3}{*}{$\begin{array}{c}\text { GG vs. } \\
\text { TT }\end{array}$} & OR $(95 \% \mathrm{CI})$ & $1.31(0.92,1.87)$ & $1.21(0.78,1.86)$ & $9.06(3.00,27.34)$ & $1.18(0.54,2.56)$ & $1.72(0.84,3.51)$ & $1.27(0.82,1.95)$ & $1.51(1.16,1.95)$ \\
\hline & $P h$ & 0.709 & 0.503 & l & 0.945 & 0.016 & l & 0.098 \\
\hline & $I^{2}$ test & $0.0 \%$ & $0.0 \%$ & l & $0.0 \%$ & $61.6 \%$ & l & $36.6 \%$ \\
\hline \multirow{3}{*}{$\begin{array}{c}\text { GG }+ \\
\text { TG vs. } \\
\text { TT }\end{array}$} & OR $(95 \% \mathrm{CI})$ & $1.27(1.01,1.60)$ & $0.86(0.69,1.07)$ & $4.80(2.86,8.03)$ & $1.26(0.82,1.93)$ & $1.25(0.81,1.93)$ & $1.15(0.96,1.37)$ & $1.25(0.98,1.59)$ \\
\hline & $P h$ & 0.006 & 0.864 & I & 0.002 & 0.000 & l & 0.000 \\
\hline & $P^{2}$ test & $62.9 \%$ & $0.0 \%$ & / & $77.1 \%$ & $83.0 \%$ & I & $77.9 \%$ \\
\hline \multirow{3}{*}{$\begin{array}{l}\text { GG vs. } \\
\text { TT + TG }\end{array}$} & OR $(95 \% \mathrm{CI})$ & $1.26(0.88,1.79)$ & $1.34(0.88,2.03)$ & $4.34(1.48,12.68)$ & $1.15(0.53,2.50)$ & $1.68(1.18,2.39)$ & $1.22(0.79,1.87)$ & $1.43(1.11,1.85)$ \\
\hline & $P h$ & 0.800 & 0.483 & 1 & 0.955 & 0.229 & 1 & 0.537 \\
\hline & $P^{2}$ test & $0.0 \%$ & $0.0 \%$ & I & $0.0 \%$ & $26.1 \%$ & I & $0.0 \%$ \\
\hline \multirow{3}{*}{ G vs. T } & OR $(95 \% \mathrm{CI})$ & $1.12(1.01,1.25)$ & $0.95(0.80,1.13)$ & $3.16(2.12,4.71)$ & $1.05(0.87,1.26)$ & $1.19(0.81,1.75)$ & $1.13(0.97,1.31)$ & $1.13(0.93,1.38)$ \\
\hline & $P h$ & 0.245 & 0.690 & l & 0.540 & 0.000 & / & 0.000 \\
\hline & $I^{2}$ test & $24.1 \%$ & $0.0 \%$ & I & $0.0 \%$ & $82.8 \%$ & l & $71.4 \%$ \\
\hline \multirow{3}{*}{$\begin{array}{c}\text { TG vs. } \\
\text { TT }\end{array}$} & OR $(95 \% \mathrm{CI})$ & $1.12(0.98,1.27)$ & $0.81(0.65,1.02)$ & $4.26(2.50,7.28)$ & $1.04(0.85,1.27)$ & $1.18(0.72,1.91)$ & $1.13(0.94,1.36)$ & $1.11(0.88,1.40)$ \\
\hline & $P h$ & 0.547 & 0.885 & l & 0.580 & 0.000 & l & 0.000 \\
\hline & $I^{2}$ test & $0.0 \%$ & $0.0 \%$ & l & $0.0 \%$ & $82.7 \%$ & / & $70.3 \%$ \\
\hline
\end{tabular}

Note: $P h$ : $P$ value of heterogeneity; If $P h>0.05$, a fixed-effect model was used to calculate OR and $95 \% \mathrm{CI}$, or else, the random-effect model was conducted.

observed a risk-increasing effect of $A D I P O Q$ rs2241766 polymorphism on DN susceptibility under GG vs. TT, and GG vs. TT+TG models. The subgroup analyses based on ethnicity and disease type also revealed such a positive correlation between the SNP and the disease risk in Caucasian, African and T2DM groups.
Results of previous studies regarding the effects of $A D I P O Q$ rs2241766 polymorphism on susceptibility to DN remains confusing. In a study among patients with T2DM, the GG genotype of the polymorphism rs2241766 was found to be significantly associated with the risk of DN after adjusting interfering factors [24]. In a study

\section{Begg's funnel plot with pseudo $95 \%$ confidence limits}

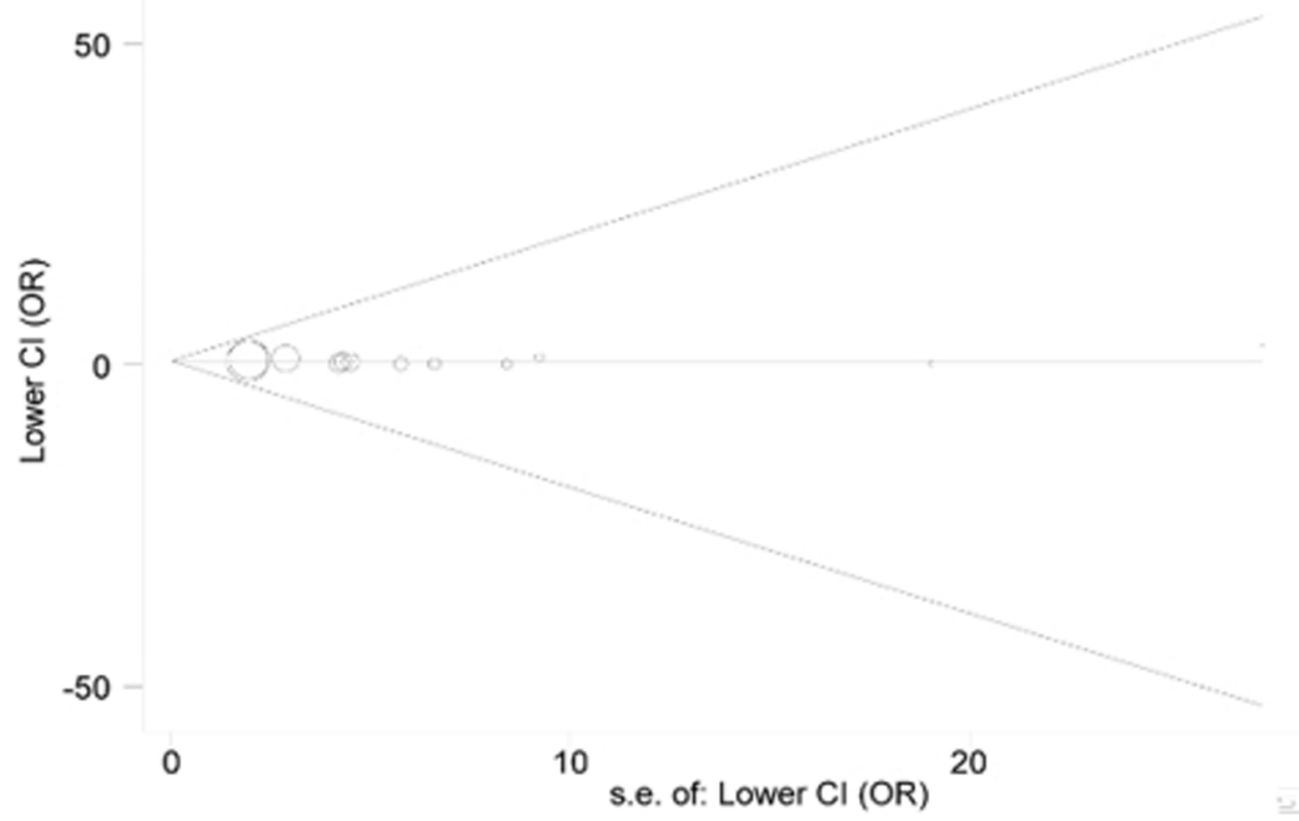

30

Figure 4: Begg's funnel plot for publication bias under GG vs. TT contrast. Each point represents a separate study for the indicated association. $\log (\mathrm{OR})$, natural logarithm of OR. Horizontal line, mean effect size. 
among Taiwanese by Chung et al., the SNP was also observed to participate the progression of DN under TT vs. GT+GG, GG/GT/TT, and allele T vs. allele $\mathrm{G}$ models among male subjects [28]. Another study among an Egyptian population also suggested a similar correlation of the SNP with DN susceptibility [29]. In contrast, Ma et al. found no independent role of rs2241766 in nephropathy development among Swedish Caucasians [25]. Neither did in three other studies by Sikka et al., Peng et al., and Rudofsky et al., respectively [27, 30, 31].

There are several possible reasons leading to the above controversy. First of all, subjects recruited by the above studies belonged to different ethnic lines. Secondly, confounding exogenous factors such as age, gender, and lifestyles were not adjusted in all studies. Thirdly, the limited number of study participants might reduce authoritativeness of some study results. Of course, some meta-analyses related to our studied topic have already been performed, such as the one by Lin et al. [41] and one by Cai et al. [42]. However, the meta-analysis by Lin and colleagues only enrolled 7 articles with 9 independent studies on our studied polymorphism while we selected 14 eligible studies from 11 papers. As for the meta-analysis by Cai and colleagues, it only concerned on DN in type 2 diabetes.

Our meta-analysis has many advantages compared to the above studies, such as a relatively larger sample size. However, some limitations of the present study should also be mentioned. To begin with, unpublished studies with null results were not enrolled in this metaanalysis, thus possibly introducing certain publication, though not significant. Next, the number of studies for stratification analyses was relatively small, thus affecting the comprehensiveness of conclusions. Finally, possible interplays of our studied SNP with other relevant factors were not analyzed owing to limited information.

All in all, the present meta-analysis indicated that ADIPOQ rs2241766 polymorphism might be related to increased risk of DN occurrence, which was more evident in Caucasian and Asian people, as well as among T2DM patients. In view of the above-mentioned limitations, these results need to be further verified in future by studies with larger scales.

\section{MATERIALS AND METHODS}

\section{Search strategy}

A comprehensive literature search was conducted in electronic databases including Embase, PubMed, Medline, Cochrane Library, Wanfang, and Chinese National Knowledge Infrastructure (CNKI) using different combinations of the following keywords: "diabetic nephropathy" or "diabetic kidney disease" or "DN", "adiponectin" or "ADIPOQ", and "polymorphism" or "variant" or "mutant" or "single nucleotide polymorphism" or "SNP". Further relevant articles were obtained by reviewing the reference lists of articles included.

\section{Selection criteria}

The following inclusion criteria were set for the present meta-analysis: (1) with both case and control subjects; (2) evaluating the correlation between $A D I P O Q$ rs2241766 polymorphism and susceptibility to DN; (3) providing sufficient information such as genotype frequency for evaluation of odds ratios (ORs) and $95 \%$ confidence intervals (95\% CIs); and (4) full-text articles with human subjects. Studies meeting any one of the following criteria were considered ineligible for the present meta-analysis: (1) conference abstracts, comments, reviews, case reports, or editorials; (2) with insufficient data for OR calculation; (3) with no control group; and (4) animal studies.

\section{Quality assessment}

We evaluated the quality of all included studies using the Newcastle-Ottawa Scale (NOS). The NOS is composed of 3 aspects: selection, comparability and exposure, with a total score of 9. According to the final score, the studies could be categorized into high-quality (score more than 6), medium-quality (score between 4 and 6) and low-quality (score less than 4).

\section{Data extraction}

The data extraction was conducted by two reviewers independently. Conflicting opinions were resolved through discussion to reach a final consensus. The items extracted from each eligible study included: first author's name, publication year, region, ethnicity, disease type, total cases and controls, genotype and/or allele frequencies in case and control groups, genotyping method, and evidence for Hardy-Weinberg Equilibrium (HWE) in controls.

\section{Statistical analysis}

STATA software (version 12.0) was used to conduct all data syntheses in this meta-analysis. The strength of relationship between ADIPOQ rs2241766 polymorphism and DN susceptibility was determined by calculating pooled ORs and 95\% CIs. The interstudy heterogeneity assumption was examined by means of $\chi^{2}$-based Q-statistic and $\mathrm{I}^{2}$ test. If heterogeneity was significant $\left(P<0.05\right.$ of the $Q$ test or $\left.I^{2}>50 \%\right)$, the summarized OR estimates were calculated utilizing the random-effects model (DerSimonian and Laird method); otherwise, the fixed-effects model (Mantel-Haenszel method) was applied. Additionally, when betweenheterogeneity was significant, we would assume meta regression analysis to identify potential sources of such heterogeneity. Begg's funnel plots and Egger's 
linear regression test were used to evaluate possible publication bias among included studies. The stability of combined results was examined by performing the sensitivity analysis, in which each of included studies was sequentially deleted and then summary ORs were recalculated so as to observe alteration between original and re-obtained ones. The statistical significance of all tests was denoted at $P<0.05$.

\section{CONFLICTS OF INTEREST}

None.

\section{GRANT SUPPORT}

This study was supported by 1) the National Natural Science Foundation of China (No. 61471399; No. 61101218); 2) National Clinical Research Center for Kidney Disease (NO. 2013BAI09B05); 3) the State Key Development Program for Basic Research of China (No. 2013CB530800); 4) Technology Project of Beijing (No. D13110700470000); 5) China Postdoctoral Science Foundation (grant NO. 2013M542447).

\section{REFERENCES}

1. Vionnet N, Tregouet D, Kazeem G, Gut I, Groop PH, Tarnow L, Parving HH, Hadjadj S, Forsblom C, Farrall M, Gauguier D, Cox R, Matsuda F, et al. Analysis of 14 candidate genes for diabetic nephropathy on chromosome $3 \mathrm{q}$ in European populations: strongest evidence for association with a variant in the promoter region of the adiponectin gene. Diabetes. 2006; 55:3166-3174.

2. Gnudi L. Angiopoietins and diabetic nephropathy. Diabetologia. 2016; 59:1616-20.

3. Tahrani AA, Bailey CJ, Del Prato S, Barnett AH. Management of type 2 diabetes: new and future developments in treatment. Lancet. 2011; 378:182-197.

4. Nyenwe EA, Jerkins TW, Umpierrez GE, Kitabchi AE. Management of type 2 diabetes: evolving strategies for the treatment of patients with type 2 diabetes. Metabolism. 2011; 60:1-23.

5. Rudnicki M, Beckers A, Neuwirt H, Vandesompele J. RNA expression signatures and posttranscriptional regulation in diabetic nephropathy. Nephrol Dial Transplant. 2015; 30:iv35-42.

6. Lizicarova D, Krahulec B, Hirnerova E, Gaspar L, Celecova Z. Risk factors in diabetic nephropathy progression at present. Bratislavske lekarske listy. 2014; 115:517-521.

7. Nichols GA, Vupputuri S, Lau H. Medical care costs associated with progression of diabetic nephropathy. Diabetes Care. 2011; 34:2374-8.

8. Ahmad J. Management of diabetic nephropathy: Recent progress and future perspective. Diabetes Metab Syndr. 2015; 9:343-58.
9. Tomić NG, Marusić S, Bozikov V, Kusec R, Bacić-Vrca V, Tadić $\mathrm{M}$. The relationship between methylenetetrahydrofolate reductase $\mathrm{C} 677 \mathrm{~T}$ gene polymorphism and diabetic nephropathy in Croatian type 2 diabetic patients. Coll Antropol. 2013; 37:789-93.

10. Zhao Y, Yang J, Zhang L, Li Z, Yang Y, Tang Y, Fu P. Association between TNF- $\alpha$-308G/A polymorphism and diabetic nephropathy risk: a meta-analysis. Int Urol Nephrol. 2013; 45:1653-9.

11. Brorsson C, Pociot F. Genetics of diabetic nephropathy in diverse ethnic groups. Contrib Nephrol. 2011; 170:8-18.

12. Fisman EZ, Tenenbaum A. Adiponectin: a manifold therapeutic target for metabolic syndrome, diabetes, and coronary disease? Cardiovasc Diabetol. 2014; 13:103.

13. Hellwege JN, Palmer ND, Mark Brown W, Ziegler JT, Sandy An S, Guo X, Ida Chen YD, Taylor K, Hawkins GA, $\mathrm{Ng}$ MC, Speliotes EK, Lorenzo C, Norris JM, et al. Empirical characteristics of family-based linkage to a complex trait: the ADIPOQ region and adiponectin levels. Hum Genet. 2015; 134:203-13.

14. Li L, Yun JH, Lee JH, Song S, Choi BC, Baek KH. Association study of $+45 \mathrm{G} 15 \mathrm{G}(\mathrm{T} / \mathrm{G})$ and $+276(\mathrm{G} / \mathrm{T})$ polymorphisms in the adiponectin gene in patients with polycystic ovary syndrome. Int J Mol Med. 2011; 27:283-7.

15. Yang H, Ye E, Si G, Chen L, Cai L, Ye C, Zhang C, Lu X. Adiponectin gene polymorphism rs $2241766 \mathrm{~T} / \mathrm{G}$ is associated with response to pioglitazone treatment in type 2 diabetic patients from southern China. PLoS One. 2014; 9:e112480.

16. Saneipour M, Ghatreh-Samani K, Heydarian E, Farrokhi E, Abdian N. Adiponectin inhibits oxidized low density lipoprotein-induced increase in matrix metalloproteinase 9 expression in vascular smooth muscle cells. ARYA Atheroscler. 2015; 11:191-5.

17. Eslamian M, Mohammadinejad P, Aryan Z, Nakhjavani M, Esteghamati A. Positive Correlation of Serum Adiponectin with Lipid Profile in Patients with Type 2 Diabetes Mellitus is Affected by Metabolic Syndrome Status. Arch Iran Med. 2016; 19:269-74.

18. Francke S, Manraj M, Lacquemant C, Lecoeur C, Lepretre F, Passa P, Hebe A, Corset L, Yan SL, Lahmidi S, Jankee S, Gunness TK, Ramjuttun US, et al. A genomewide scan for coronary heart disease suggests in IndoMauritians a susceptibility locus on chromosome 16p13 and replicates linkage with the metabolic syndrome on 3q27. Human molecular genetics. 2001; 10:2751-2765.

19. Kissebah AH, Sonnenberg GE, Myklebust J, Goldstein M, Broman K, James RG, Marks JA, Krakower GR, Jacob HJ, Weber J, Martin L, Blangero J, Comuzzie AG. Quantitative trait loci on chromosomes 3 and 17 influence phenotypes of the metabolic syndrome. Proceedings of the National Academy of Sciences of the United States of America. 2000; 97:14478-14483.

20. Jaziri R, Aubert R, Roussel R, Emery N, Maimaitiming S, Bellili N, Miot A, Saulnier PJ, Travert F, Hadjadj S, Marre M, Fumeron F. Association of ADIPOQ genetic 
variants and plasma adiponectin isoforms with the risk of incident renal events in type 2 diabetes. Nephrology, dialysis, transplantation. 2010; 25:2231-2237.

21. Savopoulos C, Michalakis K, Apostolopoulou M, Miras A, Hatzitolios A. Adipokines and stroke: a review of the literature. Maturitas. 2011; 70:322-327.

22. Apostolopoulou M, Savopoulos C, Michalakis K, Coppack S, Dardavessis T, Hatzitolios A. Age, weight and obesity. Maturitas. 2012; 71:115-119.

23. Prior SL, Tang TS, Gill GV, Bain SC, Stephens JW. Adiponectin, total antioxidant status, and urine albumin excretion in the low-risk "Golden Years" type 1 diabetes mellitus cohort. Metabolism. 2011; 60:173-9.

24. Choe EY, Wang HJ, Kwon O, Kim KJ, Kim BS, Lee BW, Ahn CW, Cha BS, Lee HC, Kang ES, Mantzoros CS. Variants of the adiponectin gene and diabetic microvascular complications in patients with type 2 diabetes. Metabolism. 2013; 62:677-685.

25. Ma J, Mollsten A, Falhammar H, Brismar K, Dahlquist G, Efendic S, Gu HF. Genetic association analysis of the adiponectin polymorphisms in type 1 diabetes with and without diabetic nephropathy. Journal of diabetes and its complications. 2007; 21:28-33.

26. Blech I, Katzenellenbogen M, Katzenellenbogen A, Wainstein J, Rubinstein A, Harman-Boehm I, Cohen J, Pollin TI, Glaser B. Predicting diabetic nephropathy using a multifactorial genetic model. PloS one. 2011; 6:e18743.

27. Rudofsky G Jr, Schlimme M, Schlotterer A, von Eynatten M, Reismann P, Tafel J, Grafe I, Morcos M, Nawroth P, Bierhaus A, Hamann A. No association of the 94T/G polymorphism in the adiponectin gene with diabetic complications. Diabetes, obesity \& metabolism. 2005; 7:455-459.

28. Chung HF, Long KZ, Hsu CC, Mamun AA, Chiu YF, Tu HP, Chen PS, Jhang HR, Hwang SJ, Huang MC. Adiponectin gene (ADIPOQ) polymorphisms correlate with the progression of nephropathy in Taiwanese male patients with type 2 diabetes. Diabetes research and clinical practice. 2014; 105:261-270.

29. El-Shal AS, Zidan HE, Rashad NM. Adiponectin gene polymorphisms in Egyptian type 2 diabetes mellitus patients with and without diabetic nephropathy. Molecular biology reports. 2014; 41:2287-2298.

30. Sikka R, Raina P, Matharoo K, Bandesh K, Bhatia R, Chakrabarti S, Bhanwer AJ. TNF-alpha (g.-308 G > A) and ADIPOQ (g. $+45 \mathrm{~T}>\mathrm{G}$ ) gene polymorphisms in type 2 diabetes and microvascular complications in the region of Punjab (North-West India). Current eye research. 2014; 39:1042-1051.

31. Peng CL, Hong YZ, Fu LP. Association of Adiponectin Gene Polymorphism in Type 2 Diabetes with Nephropathy. Journal of Medical Research. 2012; 41:156-159.
32. Ranjbar SH, Amoli MM, Sajadi M, Balaei P, Amiri P, Namakchian M, Heshmet R, Mirzaee M, Rezazadeh E, Bazzaz JT, Larijani B. Genetic association analysis of the adiponectin polymorphisms in type 2 diabetes with and without complications. Iranian Journal of Diabetes and Lipid Disorders. 2011; 10: 1-4.

33. Harving F, Svensson M, Flyvbjerg A, Schmidt EB, Jørgensen KA, Eriksen HH, Christensen JH. n-3 polyunsaturated fatty acids and adiponectin in patients with end-stage renal disease. Clin Nephrol. 2015; 83:279-85.

34. Martinez Cantarin MP, Keith SW, Waldman SA, Falkner B. Adiponectin receptor and adiponectin signaling in human tissue among patients with end-stage renal disease. Nephrol Dial Transplant. 2014; 29:2268-77.

35. Lin Z, Zhou Z, Liu Y, Gong Q, Yan X, Xiao J, Wang X, Lin S, Feng W, Li X. Circulating FGF21 levels are progressively increased from the early to end stages of chronic kidney diseases and are associated with renal function in Chinese. PLoS One. 2011; 6:e18398.

36. Yan M, Su B, Peng W, Li L, Li H, Zhuang J, Lu Y, Jian W, Wei Y, Li W, Qu S, Xu Y. Association of serum vaspin and adiponectin levels with renal function in patients with or without type 2 diabetes mellitus. J Diabetes Res. 2014; 2014:868732.

37. Tsuboi A, Watanabe M, Kazumi T, Fukuo K. Anemia and reduced renal function are independent predictors of elevated serum adiponectin in elderly women. J Atheroscler Thromb. 2013; 20:568-74.

38. Ghantous CM, Azrak Z, Hanache S, Abou-Kheir W, Zeidan A. Differential Role of Leptin and Adiponectin in Cardiovascular System. Int J Endocrinol. 2015; 2015:534320.

39. Li BT, Zhang FZ, Xu TS, Ding R, Li P. Increasing production of matrix metalloproteinases, tumor necrosis factor- $\alpha$, vascular endothelial growth factor and prostaglandin E2 in rheumatoid arthritis synovial fibroblasts by different adiponectin isoforms in a concentration-dependent manner. Cell Mol Biol (Noisy-le-grand). 2015; 61:27-32.

40. Li FY, Cheng KK, Lam KS, Vanhoutte PM, Xu A. Crosstalk between adipose tissue and vasculature: role of adiponectin. Acta Physiol (Oxf). 2011; 203:167-180.

41. Lin Z, Huang G, Zhang J, Lin X. Adiponectin gene polymorphisms and susceptibility to diabetic nephropathy: a meta-analysis. Ren Fail. 2014; 36:478-87.

42. Cai Y, Zeng T, Chen L. Association of adiponectin polymorphisms with the risk of diabetic nephropathy in type 2 diabetes: a meta-analysis. J Diabetes. 2015; 7:31-40. 